\title{
LA DEPURACIÓN DE LAS TÉCNICAS DE EQUILIBRIO ECONÓMICO APLICABLES A LA CONCESIÓN DE SERVICIOS DE TRANSPORTE REGULAR DE VIAJEROS (COMENTARIO DE LA STS 1868/2016, DE 20 DE JULIO)
}

\author{
FRANCISCO L. HERNÁNDEZ GONZÁLEZ ${ }^{1}$ \\ Universidad de La Laguna \\ fcohdez@ull.es
}

Cómo citar/Citation

Hernández González, F. L. (2017).

La depuración de las técnicas de equilibrio económico aplicables a la concesión de servicios de transporte regular de viajeros (comentario de la STS 1868/2016, de 20 de julio). Revista de Administración Pública, 202, 205-222. doi: https://doi.org/10.18042/cepc/rap.202.07

Resumen

La aplicación de la revisión de las tarifas como técnica de equilibrio económico de las concesiones de servicio público es una cuestión que está rodeada de cierta polémica; y lo mismo sucede con su compatibilidad con otras fórmulas de compensación previstas en la legislación de contratos públicos. El presente trabajo tiene por objeto analizar la Sentencia del Tribunal Supremo 1868/2016, de 20 de julio, recaída en relación con la concesión de servicio público de transporte regular de viajeros por carretera, que arroja un halo de luz sobre la materia.

\section{Palabras clave}

Concesión de servicios; riesgo y ventura; equilibrio económico del contrato; revisión extraordinaria de tarifas; transporte regular de viajeros.

1 Profesor titular de Derecho Administrativo. 


\section{Abstract}

The application of the tariff review as a technique to economically balance public service concessions is a matter surrounded by some controversy; as is its compatibility with other forms of compensation provided for in public procurement law. This paper aims to analyse Judgment No 1868/2016 of the Supreme Court, of 20 July, delivered in relation to the award of a regular public passenger road transport service, a ruling that has shed light on this matter.

\section{Keywords}

Service concession; risk and expense; economic balance of the contract; extraordinary review of tariffs; regular passenger transport. 


\section{SUMARIO}

I. INTRODUCCIÓN. II. ORÍGENES DEL CONFLICTO: LA EXISTENCIA DE DÉFICIT EN LA EXPLOTACIÓN DEL SERVICIO. III. DESESTIMACIÓN POR EL TRIBUNAL A QUO DE LAS PRETENSIONES DE LAS EMPRESAS CONCESIONARIAS: RIESGO Y VENTURA Y FALTA DE ACREDITACIÓN DEL DESEQUILIBRIO. IV. ESTIMACIÓN PARCIAL DE LAS PRETENSIONES POR EL TRIBUNAL SUPREMO: DISTINCIÓN ENTRE LA INDEMNIZACIÓN COMPENSATORIA Y LA REVISIÓN EXTRAORDINARIA DE LAS TARIFAS. V. VALORACIÓN FINAL: LA COMPATIBILIDAD DE LAS DIFERENTES TÉCNICAS.

\section{INTRODUCCIÓN}

En 1968, escribía Villar Palasí, en el prólogo al libro de Gaspar Ariño La Teoría del equivalente económico en los contratos administrativos (Madrid: IEA), que el equilibrio económico del contrato es un tema de perenne actualidad y central en la ciencia jurídico-administrativa. Transcurrido casi medio siglo, estas palabras siguen siendo oportunas, como pone de manifiesto la abundante jurisprudencia y las numerosas referencias doctrinales existentes ${ }^{2}$. El dinamismo de esta materia y el renovado interés que adquiere en nuestros días responde a diferentes causas, todas ellas interconectadas: una regulación defectuosa y en constante evolución por exigencias de la Unión Europea, combinada con los devastadores efectos de la crisis económica, que son la causa de una elevada conflictividad.

Si bien la identificación de las técnicas de equilibrio económico parece algo pacífico (desde que quedaran delimitadas por la doctrina del Consejo de Estado francés), la importancia de los intereses en juego las convierte en el centro de una constante polémica, que ofrece distintas caras: su carácter

2 Entre los trabajos más recientes cabe destacar J. F. Fernández García (2014), «Equilibrio económico y revisión de precios en los contratos administrativos», Revista Española de Derecho Administrativo, 163, págs. 145-180; y E. Vázquez Lacunsa (2016), El equilibrio económico en los contratos de servicios, Navarra: Thomson Reuters-Aranzadi, 319 págs., y la bibliografía en ellos citadas. 
excepcional y reglado, la vigencia y alcance del riesgo imprevisible, la delimitación del factum principis o, de forma más reciente, la consideración de la crisis económica como causa de equilibrio económico (como fuerza mayor o, en su caso, de riesgo imprevisible) constituyen algunos ejemplos.

Como veremos a lo largo de estas páginas, entre estas cuestiones polémicas se encuentra también la revisión de las tarifas como técnica de equilibrio económico financiero de las concesiones de servicio público. La Sentencia del Tribunal Supremo (en adelante, STS) 1868/2016, de 20 de julio (ECLI:ES:TS:2016:3839) viene a incidir sobre este tema, a raíz de la solicitud de compensación —instada en julio de 2008 — del déficit de explotación de dos concesiones de servicio público de transporte regular de viajeros por carretera en la Región de Murcia ${ }^{3}$.

En este pronunciamiento, el Tribunal Supremo anula la sentencia dictada por el tribunal a quo, estableciendo una importante doctrina, que tiene como eje central la existencia de un régimen especial de corrección del déficit de explotación, que se sustenta en la distinción entre la indemnización compensatoria y la revisión extraordinaria de tarifas.

El objeto principal del presente trabajo es analizar el contenido de ambas sentencias y sus repercusiones prácticas en la depuración de las técnicas de equilibrio económico de la concesión de servicios.

\section{ORÍGENES DEL CONFLICTO: LA EXISTENCIA DE DÉFICIT EN LA EXPLOTACIÓN DEL SERVICIO}

Lo primero será entrar en el conocimiento de los hechos que han servido de base a los órganos jurisdiccionales para adoptar sus decisiones y que podemos exponer, de forma resumida, en tres bloques:

3 Las concesiones de transporte terrestre de viajeros por carretera no son ajenas a los problemas derivados de la crisis económica. Según datos del Observatorio del Transporte de Viajeros por Carreteras, de mayo de 2015, relativos a las 86 concesiones estatales, la recaudación general de las empresas concesionarias comienza a arrojar resultados negativos de forma continuada a partir de 2006, solo corregidos en parte en 2011 y 2012 (disponibles en http://www.fomento.gob.es/NR/rdonlyres/3151FF0D-D5CE-4E3E-BB0C-66A0C840AC02/133748/ ObservatorioTransporteViajerosCarretera2015.pdf). Asimismo, un estudio elaborado por el Comité Nacional del Transporte por Carretera (organización que agrupa a las patronales del sector) venía a señalar que, en el periodo comprendido entre 2003 y 2010, estas concesiones acumulaban un déficit tarifario del 11,14\% (lo que motivó la solicitud de una revisión extraordinaria de tarifas para el año 2013 del 7,7\%). 
1. Con fecha de 21 de julio de 2008, las entidades mercantiles TRANSPORTES DE VIAJEROS DE MURCIA S.L. y BUSMAR S.L.U., en su condición de titulares de dos concesiones de servicios de transporte regular de viajeros, presentaron ante la Consejería de Obras Públicas de la Región de Murcia sendos escritos solicitando una indemnización por déficit de explotación del servicio, así como una revisión extraordinaria de las tarifas. En particular, la reclamación presentada por las empresas concesionarias se concretaba en los siguientes términos:

- La entidad mercantil TRANSPORTES DE VIAJEROS DE MURCIA, S.L.U., como titular de la concesión MURCIA-CERCANÍAS (MUR093), solicitaba una indemnización de 9483875,04 euros, correspondiente a la suma de los déficits de explotación de los últimos cinco ejercicios, incluido un razonable beneficio industrial no conseguido; y la revisión al alza de la tarifa en un $62,97 \%$, de acuerdo con un estudio económico presentado el 29 de mayo de 2008.

- Por su parte, la entidad mercantil BUSMAR, S.L.U., titular de la concesión Valle de Ricote-Playas del Mar Mayor y Menor (MUR092), reclamaba una indemnización de 891 153,69 euros, correspondiente a la suma de los déficit de explotación en idéntico periodo, incluido también un razonable beneficio industrial; y la subida de la tarifa en un $40,75 \%$, de acuerdo con el estudio económico de igual fecha.

2. Los argumentos expuestos por las entidades reclamantes eran similares, concretándose en los siguientes aspectos:

- En ambas concesiones, la prestación del servicio había sido deficitaria durante, al menos, los últimos cinco ańos.

- Esta situación era conocida por la Administración regional que, pese a todo, ni había procedido a subir las tarifas en la cuantía necesaria para cubrir los costes reales, ni a suprimir servicios (más al contrario, había instado a su mantenimiento e incluso, en ocasiones, a aumentar los existentes), como tampoco había aportado recursos económicos suficientes para paliar esta situación.

- Como consecuencia del mencionado déficit de explotación, el equilibrio económico de la concesión y el de la empresa se había roto.

- Finalmente, consideran que lo reclamado tiene amparo en el artículo 19.1 de la Ley 16/1987, de 30 de julio, de Ordenación de los Transportes Terrestres (en adelante, LOTT), y en el artículo 88.1 del Real Decreto 
1211/1990, de 28 de septiembre, por el que se aprueba su Reglamento de desarrollo (en adelante ROTT) ${ }^{4}$.

A pesar de los datos expuestos, ambas reclamaciones fueron desestimadas por silencio administrativo, lo que condujo a las dos empresas concesionarias a formalizar recurso contencioso-administrativo ante el Tribunal Superior de Justicia (en adelante, TSJ) de Murcia, reiterando idénticas peticiones (recurso 928/2011). En su defensa, junto con la demanda, aportaron un informe sobre el resultado de explotación de las concesiones administrativas relativo a los años 2005, 2006 y 2007.

3. Como era de esperar, la Administración autonómica se opuso al mencionado recurso, formulando las siguientes consideraciones:

- En primer lugar, que la gestión se realiza a riesgo y ventura del concesionario, no existiendo circunstancia alguna que determine la existencia de un riesgo imprevisible.

- En segundo lugar, que la petición de los actores resulta desproporcionada $y$ carente de fundamento, en la medida en que la Administración ha realizado múltiples actuaciones para velar por el mantenimiento del equilibrio económico de la concesión.

- En tercer lugar, que entre los años 2004 y 2009 las concesionarias no han presentado auditoría externa contable ni informe de gestión que permi$\tan$ acreditar la existencia de dicho desequilibrio.

- En cuarto lugar, que la formalización de determinados convenios de colaboración y contratos-programa para el fomento y mejora del transporte público, han redundado en beneficio para las empresas concesionarias.

- Y, en quinto y último lugar, que las modificaciones del servicio, en su mayoría, fueron instadas por las empresas concesionarias, sin plantear revisiones tarifarias y sin hacer reserva expresa de su reclamación, ni instar anualmente dicha revisión.

4 El más completo análisis del sector en J. A. Razquín Lizarraga (1995), Derecho Público del transporte por carretera, Navarra: Aranzadi, 690 págs.; y los diferentes trabajos publicados en P. Menéndez (2014), Régimen Jurídico del Transporte Terrestre: carreteras y ferrocarril, 2 tomos, Navarra: Thomson Reuters-Aranzadi; en particular las colaboraciones de F. J. Villar Rojas (págs. 635-689) y de D. Blanquer Criado (págs. 691-749). 
En apoyo de sus argumentos, la Administración demandada aportó informes de una empresa auditora sobre la revisión del desequilibrio económico de la explotación en dichas concesiones, que fueron ratificados en juicio.

\section{DESESTIMACIÓN POR EL TRIBUNAL A QUO DE LAS PRETENSIONES DE LAS EMPRESAS CONCESIONARIAS: RIESGO Y VENTURA Y FALTA DE ACREDITACIÓN DEL DESEQUILIBRIO}

Planteado el conflicto en los términos expuestos, la Sentencia del TSJ de Murcia 958/14, de 28 de noviembre (ES:TSJMU:2014:2931) desestimó el recurso presentado por las empresas concesionarias, al concluir que no se había producido un desequilibrio económico de las concesiones de transporte. De forma resumida, los argumentos que ofrece el tribunal a quo para rechazar las pretensiones de las partes son los siguientes:

En primer lugar, estima que no procede el derecho a obtener una reparación indemnizatoria por cuanto la prestación del servicio se lleva a cabo a riesgo y ventura de las empresas concesionarias (art. I7 de la Ley 16/1987), que deberán cumplir el objeto del contrato conforme a los términos convenidos, incluso si se producen acontecimientos que, no siendo extraordinarios, incidan de una forma negativa en su economía. En este sentido, sostiene la Sentencia de instancia que no consta que la alteración de la economía del contrato haya tenido lugar como consecuencia de decisiones administrativas (factum principis o ejercicio del ius variandi) o de circunstancias que determinen la existencia de un riesgo imprevisible.

$Y$, en segundo lugar, considera el tribunal que tampoco queda suficientemente acreditada la existencia de déficit de explotación, restando valor probatorio a la prueba propuesta por los reclamantes frente a los informes de auditoría presentados por la Administración demandada ${ }^{5}$, de los que deduce los siguientes elementos probatorios:

A. La recurrente fija el beneficio empresarial en un $15 \%$, al amparo de dos órdenes de la Generalidad de Cataluña que no son de aplicación; siendo así que el artículo 131 del Real Decreto 1098/2001 fija el beneficio industrial en un $6 \%$ del presupuesto de ejecución material, que, si bien viene referido

5 Entiende el tribunal a quo que los datos que ofrece la actora para hacer sus cálculos carecen de la suficiente y necesaria justificación para que puedan ser aceptados sin más (además, estos se refieren a los ejercicios 2005-2007, mientras que la reclamación de indemnización alude a los últimos cinco ejercicios). 
al contrato de obras, se puede entender de aplicación a los demás tipos de contrato.

B. No todos los años del período que se reclama tuvieron resultados negativos, dado que la concesión 092 los tuvo en 2005, 2007 y 2008, mientras que la concesión 093, únicamente, en 2007 y 2008. Por lo tanto, rechaza la petición de revisión de tarifas, porque entiende que los déficit que puedan haberse acreditado en ejercicios anuales aislados no son suficientes para acordar dicha medida ${ }^{6}$.

C. Las empresas concesionarias contabilizaban de forma conjunta todas las concesiones, tanto autonómicas como municipales, así como los servicios discrecionales que prestaban. Al respecto, destaca los siguientes «datos objetivos»:

- Que la Sociedad incluye en su contabilidad ingresos y gastos de varias actividades de transporte, ya que no solo desarrolla los servicios propios de la concesión MU-092 y MU-093, sino que además presta servicios de transporte de viajeros de la concesión para transporte de viajeros en el municipio de Murcia y sus pedanías y servicios de carácter discrecional y escolar.

- Que la Sociedad emplea recursos comunes, tanto materiales como humanos, para la prestación de las diferentes actividades de transporte.

- Que la Sociedad no tiene una contabilidad de costes que permita determinar de forma absolutamente fiable las imputaciones de ingresos y gastos para cada una de las líneas de las concesiones que explota, así como de los servicios discrecional y escolar.

- Que la estructura de costes de explotación de la Sociedad se encuentra por encima de la media de otras empresas del sector en cada una de las partidas.

A la vista de lo expuesto, el TSJ de Murcia llega a una conclusión que puede parecer obvia:

[...] no podemos concluir que se haya producido un desequilibrio financiero de las concesiones ya que, como hemos dicho en otras ocasiones, la teoría de la imprevisión no puede ser entendida como una garantía de beneficio para el contratante, ni tampoco como un seguro destinado a cubrir las posibles

6 A juicio del tribunal de instancia, no hay base para considerar desequilibrio concesional cualquier ejercicio con resultado negativo y menos aún aquellos en que, siendo positivo, el beneficio no alcanza el $15 \%$. 
disminuciones de beneficio surgidas por malas decisiones empresariales; por tanto, el recurso ha de ser desestimado.

\section{ESTIMACIÓN PARCIAL DE LAS PRETENSIONES POR EL TRIBUNAL SUPREMO: DISTINCIÓN ENTRE LA INDEMNIZACIÓN COMPENSATORIA Y LA REVISIÓN EXTRAORDINARIA DE LAS TARIFAS}

Interpuesto recurso de casación por las dos entidades mercantiles, el Tribunal Supremo lo resuelve por Sentencia 1868/2916, de 20 de julio (ES:TS:2016:3839), que estima parcialmente el recurso interpuesto, reconociendo el derecho de dichas entidades a que la Administración proceda a la revisión de las tarifas de las concesiones litigiosas, de acuerdo con los parámetros y alcance fijados en la propia Sentencia. De su contenido, cabe extraer cuatro consideraciones de interés.

$1^{\circ}$. Distinción entre indemnización compensatoria del desequilibrio financiero y revisión de tarifas

Siguiendo un adecuado orden, el TS se detiene, en primer lugar, en concretar el régimen jurídico aplicable al presente conflicto. Este viene determinado por los artículos 17 y 19 de la LOTT (relativo, el primero, al principio de riesgo y ventura, y, el segundo, a la revisión de las tarifas), en los términos vigentes en el momento de presentación de las solicitudes por las empresas reclamantes. En este sentido, precisa que la interpretación de ambos preceptos debe realizase conjuntamente, de cuya hermenéutica resulta que «son cuestiones diferentes, por un lado, la atinente a determinar cuándo resultaran procedentes indemnizaciones alzadas reequilibradoras de la economía del contrato $\mathrm{y}$, por otro, la referida a acordar una revisión de las tarifas establecidas en el contrato».

Por lo que respecta a las alteraciones de la economía del contrato, habrá que estar al principio de riesgo y ventura previsto en el artículo 17 LOTT (apartado primero) y a las reglas generales sobre el reequilibrio económico-financiero previstas en la legislación de contratos públicos (al que remite el apartado segundo). En palabras del propio Tribunal:

Desde esta distinción, ya ha de decirse que, en lo que concierne a las alteraciones de la economía del contrato, la expresa aplicabilidad del principio de riesgo y ventura, que proclama ese mencionado artículo 17 LOTT, hace que el contratista, al igual que se beneficia de las mayores ventajas que en relación con las previstas le depare 
la dinámica del contrato, ha de soportar la mayor onerosidad que para él pueda significar su ejecución; $y$, consiguientemente, para que proceda el reequilibrio financiero del contrato mediante una indemnización compensatoria, regirá la regla general, presente en nuestra legislación de contratos públicos, de que no bastará con que su economía haya resultado alterada sino que será preciso que la causa de esa alteración haya sido el "factum principis», el ejercicio del «ius variandi» o la concurrencia de circunstancias calificables de "hecho imprevisible».

En consecuencia, la STS llega a la conclusión de que la decisión de la Sala de instancia de denegar la petición indemnizatoria fue correcta, por no concurrir ninguna de las circunstancias expresadas; resultando, pues, injustificados los reproches que se hacen por los recurrentes ${ }^{7}$.

$2^{\circ}$. La doctrina del TS en relación con la articulación de los principios de riesgo y ventura y de restablecimiento de la economía del contrato

Para reforzar esta primera conclusión, el TS reitera su doctrina sobre la aplicación del principio de riesgo y ventura y la garantía de la equivalencia económica de las contraprestaciones, que se encuentra recogida en sus Sentencias de 28 de enero de 2015 (recurso 449/2012) y de 28 de octubre de 2015 (recurso 2785/2014), y que se concreta en las cuatro reglas siguientes:

\section{A. La eficacia vinculante del contrato y la invariabilidad de sus cláusulas}

La primera regla consiste en confirmar que el principio de la eficacia vinculante del contrato y de la invariabilidad de sus cláusulas es una norma general que rige en nuestro ordenamiento jurídico tanto para la contratación privada como para la contratación administrativa. Así se desprende tanto del artículo 1091 del Código Civil como de la legislación de contratos administrativos más reciente: artículo 94 del TR/LCAP de 2000 y artículos 208 y 209 del TR/ LCSP de 2011.

En su tercer motivo de casación, los recurrentes venían a sostener que la Sala a quo había efectuado una interpretación distorsionada del artículo 19 LOTT, al exigir que la alteración de la economía del contrato fuera consecuencia de una decisión de la Administración o de la concurrencia de un «hecho imprevisible», cuando — a su juiciopara tener derecho al reequilibrio económico bastaba con la existencia de un déficit en la explotación, cualquiera que fuera su causa; esto es, un desequilibrio derivado simplemente de un incremento de los costes, aunque sus causas fueran ajenas tanto a la Administración como al concesionario. 


\section{B. El principio de riesgo y ventura incluye la frustración de las expectativas} económicas

La segunda regla es que la contratación administrativa se caracteriza también por llevar inherente un elemento de aleatoriedad de los resultados económicos del contrato, al estar expresamente proclamado por la ley el principio de riesgo y ventura del contratista (artículos 98 del TR/LCAP de 2000 y 215, 231 y 242 del TR/LCSP de 2011). Este elemento de aleatoriedad implica que la frustración de las expectativas económicas que el contratista tuvo en consideración para consentir el contrato no le libera de cumplir lo estrictamente pactado ni, consiguientemente, le faculta para apartarse del vínculo contractual o para reclamar su modificación ${ }^{8}$.

\section{Con carácter general, el reequilibrio económico solo procede en los supues-} tos tasados por el legislador

La tercera regla viene a recordar que, en nuestro ordenamiento jurídico, ha sido tradicional establecer unas tasadas excepciones a esa aleatoriedad de los contratos administrativos, consistentes en reequilibrar la ecuación financiera del contrato únicamente cuando se ha producido una ruptura de la misma por causas imputables a la Administración (ius variandi o factum principis), o por hechos que se consideran «extra muros» del normal «alea» del contrato por ser reconducibles a los conceptos de fuerza mayor o riesgo imprevisible. Esto significa que no toda alteración del equilibrio de las prestaciones del contrato da derecho al contratista a reclamar medidas dirigidas a restablecer la inicial ecuación financiera del vínculo, sino únicamente aquellas que sean reconducibles a esos tasados supuestos de ius variandi, factum principis, y fuerza mayor o riesgo imprevisible?

8 En este sentido se habían expresado ya las SSTS de 24 de abril de 1985 (RJ 1985/2229) y de 9 de octubre de 1987 (ES:TS:1987:6277).

9 Con anterioridad, precisa el TS que «el equilibrio financiero de cualquier concesión es una fórmula excepcional que debe coordinarse con el principio de riesgo y ventura al objeto de impedir que esa excepcionalidad se convierta en una garantía ordinaria de los intereses del concesionario» (STS de 25 de abril de 1986, ES:TS:1986:2081), «a modo de seguro gratuito que cubra todos los riesgos de la empresa, trasladándolos íntegros a la "res publica" en contra de lo que constituye la esencia misma de la institución y sus límites naturales» (STS de 17 de julio de 1991, ES:TS:1991:4248). En palabras del Consejo de Estado, su aplicación requiere «una quiebra radical del equilibrio económico financiero contractual, por su excesiva onerosidad, por su imposible compensación mediante los mecanismos contractuales regulares (la revisión de 
Asimismo, recuerda el TS que esa regulación tasada de los supuestos excepcionales de restablecimiento del equilibrio económico del contrato ha estado presente en la sucesiva legislación de contratos públicos. Así, los artículos 144 y 163 del TR/LCAP de 2000, que regulaban medidas de reparación para los supuestos de fuerza mayor y ejercicio del ius variandi; el artículo 248.2 de ese mismo TR/LCAP, introducido por la Ley 13/2003, de 23 de mayo, reguladora del contrato de concesión de obras públicas, que refiere el deber de la Administración de restablecer el equilibrio económico del contrato a los supuestos de ius variandi, fuerza mayor, factum principis y previsiones del propio contrato; y el artículo 258.2 del TR/LCSP de 2011, que viene a reproducir el contenido del anterior precepto. Y en esa misma línea se han movido los artículos 24 y 25 de la Ley 8/1972, de 10 de mayo, de construcción, conservación y explotación de autopistas en régimen de concesión, que vienen a contemplar desequilibrios debidos a decisiones de la Administración.

\section{El propio contrato o una ley especial pueden establecer medidas singulares}

Finalmente, señala la Sentencia comentada que, más allá de los supuestos tasados en la regulación general de la contratación pública, el reequilibrio solo procederá cuando lo haya previsto el propio contrato y cuando una ley especial regule hipótesis específicas de alteración de la economía inicial del contrato y establezca medidas singulares para restablecerla. En otros términos, admite el TS que el legislador sectorial pueda introducir un régimen especial del restablecimiento económico del contrato, que se aparte del régimen general.

3o. Existencia de una regulación especial sobre la alteración de la economía del contrato en la legislación de transporte

En virtud de esta última consideración, el TS estima que la decisión de la Administración, de no proceder a la revisión de las tarifas solicitadas por las empresas concesionarias, constituye una infracción del artículo 19 de la LOTT de 1987, al entender que hay en el mismo "una regulación especial de la alteración de la economía del contrato y de sus especificas consecuencias que se aparta del régimen general que antes ha sido expuesto, y que se concreta únicamente en el derecho a solicitar una revisión de las tarifas para ejercicios futuros y

precios, cuando procede, entre otros) y por suponer una frustración completa de los presupuestos contractuales (todo ello conjuntamente)» (Dictamen 1332/2012, de 10 de enero de 2013, reiterados en otros posteriores). 
no otorga derecho a pedir indemnizaciones por las pérdidas sufridas antes de solicitarse la revisión de tarifas» ${ }^{10}$.

Es así que, constando una situación de déficit en un determinado ejercicio (que la propia Administración demandada reconoce), la revisión resulta procedente para el siguiente ejercicio, siempre que hubiera sido solicitada por el titular de la concesión (como ha sucedido en el presente supuesto). Por consiguiente, concluye que no ha sido acertado el criterio de la sentencia recurrida de no haber ponderado dicho déficit en orden a decidir la improcedencia de la solicitud de revisión de tarifas.

\section{Criterios aplicables a la revisión de las tarifas}

En virtud de lo expuesto, la Sentencia ratifica la improcedencia de la indemnización solicitada, pero reconoce el derecho a que, en respuesta a las solicitudes de 21 de julio de 2008 presentadas por las sociedades recurrentes, la Administración acuerde la revisión de las tarifas de ambas concesiones.

Con todo, la decisión del Tribunal no finaliza con este reconocimiento, sino que también establece los términos y alcance de dicha revisión, con el fin - presumible- de evitar un nuevo conflicto, derivado de la interpretación de los criterios aplicables. En consecuencia, formula las tres precisiones siguientes.

En primer lugar, reconoce un valor probatorio superior a la prueba pericial propuesta por la Administración, en la medida que: a) es más completa la descripción que efectúa de las partidas de gastos e ingresos que toma en consideración, lo que hace aparecer más verosímiles y rigurosas sus conclusiones; y b) establece una comparación de la estructura de costes que tiene por constatada con la media de las empresas del sector, las previsiones del Pliego y los estándares del Observatorio de Costes del Transporte de Viajeros (ACOTRAVI), ofreciendo así las condiciones de normalidad que el artículo 19 de la LOTT exige necesariamente tomar en consideración para valorar el alcance del desequilibrio financiero apreciado.

En segundo lugar, establece los parámetros o criterios a que habrá de ajustarse dicha revisión de tarifas, y que son los siguientes:

10 Como precisa el TS, el artículo 19 de la LOTT, «en su apartado 2, dispone la cobertura económica que han de cumplir las tarifas para que pueda considerarse que se mantiene el equilibrio económico del servicio, así como la normalidad que ha de concurrir a estos efectos en cuanto a las condiciones de productividad y organización; $y$, en su apartado 3, regula la revisión de las tarifas como consecuencia única, pero obligada, de la alteración de la economía del servicio que se haya producido». 
10. El punto de partida es el déficit que para una y otra concesión ha sido apreciado en el ejercicio 2008 de acuerdo con los informes de auditoría de 22 de junio de 2011 (solo desde esta fecha podrá considerarse justificado dicho déficit).

$2^{\circ}$. El beneficio empresarial ha de ser del 6\%, que señala como procedente la sentencia recurrida (en tanto que la parte demandante no ha aportado prueba con entidad suficiente para demostrar que la Administración haya manifestado su voluntad de asignar a este concepto un porcentaje superior).

$3^{\circ}$. Se aplicarán mecanismos de corrección de las partidas de costes que excluyan los excesos que los mencionados informes han constatado sobre la media del sector (para así dar cumplimiento a las circunstancias de normalidad en la organización que dispone el artículo 19.2 LOTT).

40. El resultado de la revisión podrá absorber las mejoras inherentes a las modificaciones de las concesiones, posteriores a la solicitud de revisión, que hayan sido consentidas por las sociedades aquí recurrentes.

Finalmente, la sentencia hace una última puntualización, no menos importante: el derecho a la revisión de tarifa que se reconoce no significa que se otorgue necesariamente un incremento de la misma, sino que habrá que estar al resultado de revisión que se derive de su cálculo, efectuado según los parámetros y criterios anteriores.

\section{VALORACIÓN FINAL: LA COMPATIBILIDAD DE LAS DIFERENTES TÉCNICAS}

Como ha quedado explicado, la sentencia comentada diferencia entre la indemnización compensatoria del desequilibrio económico por circunstancias extraordinarias e imprevisibles y la revisión de tarifas por la existencia de déficit de explotación. Establecida esta distinción, el problema radica en saber si constituyen técnicas de reequilibrio económico compatibles entre sí o, si por el contrario, la segunda desplaza a la primera ${ }^{11}$.

La respuesta de la cuestión planteada requiere atender al régimen de financiación de las concesiones de servicio de transporte de viajeros, que establece la legislación sectorial. De acuerdo con esta normativa, el contratista tiene una doble vía de retribución: a) mediante la percepción de las tarifas que

11 Con carácter general, defiende esta compatibilidad J. F. Fernández García (2014: 170-171). 
abonen los usuarios; y b) a través de las compensaciones, económicas o de otra indole, que se establezcan para cubrir la totalidad de los costes de explotación, en el caso de tarifas que respondan a precios políticos o sociales (art. 19.2 de la LOTT $)^{12}$. A su vez, como matiza Villar Rojas, sucede que las tarifas están sujetas a dos supuestos de revisión ${ }^{13}$ : una ordinaria (de carácter general), que se lleva a cabo dentro del segundo trimestre de cada ańo y que equivale a la revisión de precios de la contratación administrativa común (arts. 19.5 de la LOTT y 87 del ROTT); y otra extraordinaria (que opera individualmente, de oficio o a instancia del contratista), que se produce cuando «las partidas que integran su estructura de costes hayan sufrido una variación que altere significativamente, al alza o a la baja, el equilibrio económico del contrato» (arts. 19.3 de la LOTT y 88 del ROTT).

Lo anterior debe entenderse, además, sin perjuicio de las posibles indemnizaciones compensatorias que puedan aplicarse en virtud de lo dispuesto en la legislación de contratos del sector público sobre régimen económico del contrato de gestión de servicios públicos (tal como establece el art. 17.2 de la LOTT) ${ }^{14}$; siempre que tenga lugar una alteración sustancial de la economía del contrato que ponga en peligro la continuidad del servicio público ${ }^{15}$.

12 Como apunta J. A. Razquín Lizarraga (1995: 514-521), en materia de transporte regular de viajeros, el principio de riesgo y ventura se verá corregido por el principio de cobertura suficiente o de suficiencia tarifaria (mediante la fijación de tarifas que cubran el coste real del servicio), que tiene como cláusula de cierre, para el caso de no darse esa suficiencia, el principio y derecho del concesionario a la retribución justa o suficiente.

13 F. J. Villar Rojas, «La concesión del servicio de transporte: carretera y ferrocarril», en P. Menéndez (2014: 635-658). Señala este autor que, en su aplicación, la Administración acude primero al art. 19.3 de la LOTT (revisión por desequilibrio económicofinanciero) para, a continuación, una vez establecidos sus valores, aplicar el art. 19.5 de la LOTT, absorbiendo el incremento ya otorgado (nota 48).

14 Según este precepto, no obstante el principio de riesgo y ventura, «en la explotación de aquellos transportes a los que esta ley atribuye el carácter de servicios públicos de titularidad de la Administración se aplicarán las disposiciones de la Unión Europea en materia de servicios públicos de transporte de viajeros por ferrocarril y carretera $y$, en su caso, lo dispuesto en la legislación sobre contratos del sector público sobre régimen económico del contrato de gestión de servicios públicos».

15 Una reiterada línea jurisprudencial delimita el alcance de la obligación de compensar la mayor onerosidad sobrevenida de la concesión en función de la causa determinante del desequilibrio económico, diferenciando entre: a) modificaciones introducidas por ius variandi o por factum principis, "que no deben ser asumidas por el contratista, ni siquiera para compartir el perjuicio con quien lo ocasionó»; y b) el desequilibrio producido por causas sobrevenidas e imprevisibles, en los que el perjuicio económico debe 
En consecuencia, ambas medidas económicas, esto es, revisión extraordinaria de tarifas e indemnización compensatoria (por el ejercicio del ius variandi, factum principis, riesgo imprevisible y fuerza mayor), constituyen técnicas de equilibrio económico aplicables a las concesiones de servicios de transporte de viajeros por carretera, en tanto que responde a situaciones diferentes.

Hay que decir que esto supone una excepción a la regla general predicable de la revisión de precios, en los contratos de obras. En efecto, es doctrina reiterada del Consejo de Estado, recaída en relación con el incremento de precios de los materiales en ese tipo de contratos, que la función de las cláusulas de revisión no es garantizar el mantenimiento de precios de mercado durante el periodo contractual (esto es, mantener la equivalencia económica de las prestaciones); sino la de "disponer una limitación equitativa al riesgo empresarial», mediante un modelo uniforme para todo contratista, evitando así que puedan quedar excluidas del mercado las empresas con menor capacidad ante las fluctuaciones de precios. En este sentido, sostiene el máximo órgano consultivo que la revisión de precios no es más que «una cláusula de estabilización, de las llamadas de índice, directamente encaminada a proteger contra la pérdida del poder adquisitivo de la moneda». Llevar su alcance — afirma - hasta el extremo de cubrir enteramente el riesgo empresarial «supondría sustituir en el contrato de obra el principio de riesgo y ventura por el de mantenimiento del equilibrio económico financiero» ${ }^{16}$.

No obstante, dicha doctrina solo resulta aplicable a la revisión ordinaria de las tarifas, pero no a la revisión extraordinaria prevista en el artículo 19.3 de la LOTT. De hecho, a diferencia de lo que sucede en el contrato de obras, la revisión extraordinaria de las tarifas por razón del desequilibrio económico es una característica del contrato de concesión, que está presente tanto en la

compartirse en adecuada proporción entre ambos sujetos afectados, por ser la Administración ajena a la producción del mismo, de tal modo que la cuantía de la compensación no sea tan escasa que la haga ineficaz para impedir la ruina de la concesión, ni tan excesiva que desplace el riesgo normal de la empresa a la Administración concedente (entre otras, SSTS de 20 de febrero de 1980, ES:TS:1980:2703; 25 de abril y de 20 de diciembre de 1986, ES:TS:1986:2081 y ES:TS:1986:7263; 21 de febrero de 1998, ES:TS:1998:1170; y STS de 23 de febrero de 2001, ES:TS:2001:1291).

16 Esto le lleva a descarta la posibilidad de indemnizar como riesgo extraordinario el incremento de valor de los materiales que no quede cubierto mediante la aplicación de las fórmulas de revisión de precios. En este sentido se pronuncian, por ejemplo, los Dictámenes 1333/2012, de 10 de enero de 2013, y 620/2014, de 23 de julio; que, sin embargo, admiten un régimen especial aplicable a las concesiones de gestión de servicio público o de interés económico general, donde opera — aún con ciertas modulaciones - esta mutación de principios. 
legislación de contratos públicos (arts. 258.3, para la concesión de obras; y 282.5 TRLCSP, para la concesión de servicios) ${ }^{17}$ como en el Reglamento de Servicios de las Corporaciones Locales (arts. 127.2, b) y 152); precisando este último precepto que «la revisión extraordinaria procederá de oficio o a petición de la Empresa o concesionario, siempre que se produjere un desequilibrio en la economía de la Empresa o de la concesión, por circunstancias independientes a la buena gestión de una u otro» ${ }^{18}$.

Ahora bien, una vez incorporado un determinado sobrecoste en la revisión de la tarifa ${ }^{19}$ no puede pretenderse también su compensación mediante una indemnización por circunstancias imprevisibles, dado que no es posible compensar el mismo desequilibrio económico por dos vías diferentes, pues ello daría lugar a un enriquecimiento injusto por parte del concesionario.

Además de lo indicado, el análisis del régimen de financiación de la concesión de transporte regular de viajeros nos lleva a una conclusión final: se trata de un contrato económicamente garantizado, en el que no existe un riesgo operativo significativo por parte del concesionario, que tiene garantizado el importe de las inversiones y de los costes de explotación. Por lo tanto, de acuerdo con las nuevas directivas de contratación pública de

17 Preceptos que mantienen su redacción tras la nueva regulación del régimen de revisión de precios de los contratos del sector público que introduce la Ley 2/2015, de 30 de marzo, de desindexación de la economía española (art. 6 y D.F. tercera), que establece una prohibición general de actualización de precios según índices generales (sobre la aplicación de esta reforma se puede consultar la Recomendación de la Junta Consultiva de Contratación Administrativa del Estado de 19 de mayo de 2015).

18 Señala la STS de 14 de octubre de 1982 (RJ 1982/6367) que, «aunque la revisión de precios ha sido pensada doctrinal y legalmente con una orientación dirigida básicamente al contrato de obras públicas, sin embargo, así como en éste trata de modular la rigidez del principio de riesgo y ventura para el contratista, cuando la institución se trasvasa... a la concesión de un servicios público, el principio inspirador de la misma es el del equilibrio de la retribución económica del concesionario al que se refiere, con carácter general, el art. 126.2,b) del Reglamento de Servicios». Sobre el régimen singular de la concesión de servicios se pueden consultar también las SSTS de 23 de diciembre de 1980 (ES:TS:1980:2803), 20 de diciembre de 1986 (ES:TS:1986:7263), 3 de julio de 1987 (ES:TS:1987:4694) y de 20 de abril de 2004 (ES:TS:2004:2573).

19 Este es el caso, por ejemplo, de la Orden de 6 de marzo de 2008, de la Consellería de Política Territorial, Obras Públicas y Transporte de Galicia, que - con carácter excepcional para el ejercicio 2008- incorpora, a la fórmula aplicable a la revisión anual de las tarifas, el sumando de 0,00425, con el fin de incluir en la tarifa el suplemento de aire acondicionado y de paliar los sobrecostes sufridos por los operadores en los primeros meses del año derivados de las condiciones macroeconómicas (art. 1.3). 
2014, nos encontramos realmente en presencia de un contrato público de servicios (y no ante una concesión de servicios), con plena independencia de que el objeto del contrato sea la prestación de un servicio público o de que la remuneración del operador dependa — total en su mayor parte- de las tarifas abonadas por los usuarios ${ }^{20}$.

20 Sobre el concepto comunitario de concesión véase F. L. Hernández González (2015), «La nueva Directiva de concesiones. Un largo viaje con final esperado», en Gimeno, Gallego, Hernández y Moreno, Las nuevas Directivas de contratación pública, Observatorio de la Contratación Pública, Navarra: Thomson Reuters-Aranzadi, págs. 178-190; del mismo autor (2016), "The evolving concept of woks and service concessions in European Union Law», Public Procurement Law Review, 2, págs. 35-60; así como los trabajos publicados en Baño León (coord.), Memorial para la reforma del Estado, Libro Homenaje al prof. S. Muñoz Machado, vol. III, Madrid: CEPC, por el autor de este trabajo, págs. 2449-2480, y por L. Mellado Ruiz, págs. 2481-2509. En este sentido, cabe recordar que la norma de cabecera del grupo normativo que rige el contrato de gestión de servicio público de transporte urbano es el Reglamento CE 1370/2007, de 23 de octubre, sobre los servicios públicos de transporte de viajeros por ferrocarril y carretera, que permite que sea una u otra modalidad contractual (art. 5). En todo caso, el divorcio existente entre las categorías de la Unión Europea y el derecho interno no puede convertirse en fuente generadora de conflictos, que ponga en peligro los principios de continuidad y regularidad del servicio público. 